\title{
Wirksame Zulassung oder kaum umsetzbares Bürokratiemonster?
}

\author{
Jürg Schlup \\ Dr. med., Präsident der FMH
}

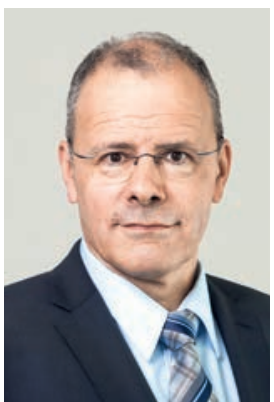

Einigkeit besteht in der aktuellen Diskussion über die Zulassung lediglich in einem Punkt: Wir benötigen eine wirksame Zulassungssteuerung, die dem Versorgungsbedarf und den Qualitätsansprüchen unseres Gesundheitswesens entspricht. Kaum Einigkeit besteht leider darüber, wie dies am besten erreicht werden kann.

Seit Jahren präsentiert die Ärzteschaft eine wirksame und einfach umsetzbare Lösung: Sie setzt auf eine dreijährige Spitaltätigkeit in der Schweiz sowie den Nachweis von Sprachkompetenz als Voraussetzungen für eine Zulassung (siehe auch unten). Dagegen legte der Bundesrat im Mai 2017 einen Gesetzesentwurf (18.047) vor, der eine administrativ sehr aufwendige Regulierung vorsieht [1]. Spätestens seit dieser Entwurf im Dezember 2018 vom Nationalrat diverse Änderungen erfuhr, ist klar: «Es droht ein neues Bürokratiemonster» [2] - wie die Helsana formuliert.

Soll künftig jede Änderung des Arbeitspensums von 19331 ambulant tätigen Ärztinnen und Ärzten die Kantonsverwaltungen beschäftigen?

Den grössten Teil des Bürokratieschubs hätten die Kantonsverwaltungen zu bewältigen. Es bräuchte nicht nur eine detaillierte Angebotsplanung; für eine $\mathrm{Zu}$ lassungssteuerung gemäss festgelegten Ärztezahlen müsste die Verwaltung regelmässig sämtliche ärztlichen Arbeitspensen überprüfen. Die 19331 im ambulanten Sektor tätigen Ärztinnen und Ärzte der Schweiz [3] müssten damit künftig jede Änderung ihres Pensums ihrem Kanton zur Kenntnis geben bzw. von diesem bewilligen lassen. Passen Freipraktizierende also ihr Praxispensum an, weil sie - langfristig oder zeitweise - verstärkt Aufgaben als Schularzt, Vertrauensarzt oder Gutachter wahrnehmen oder die Arbeitszeitreduktion anderer Ärztinnen und Ärzte auffangen, liesse sich das künftig nicht mehr unkompliziert unter Kolleginnen und Kollegen absprechen - sondern würde neu über kantonale Schreibtische wandern. Ironischerweise hätten die Kantone - trotz des hohen Regulierungsaufwands - nicht mehr, sondern weniger Handlungsspielraum. Durch die geplante Abschaffung der Bedürfnisklausel in Art. 55a KVG und die Vorgabe zwingender Zulassungsvoraussetzungen in Art. $37 \mathrm{KVG}$ könnten sie im Fall einer Unterversorgung nicht mehr flexibel reagieren. Die in Art. 55a neu geplante Vorgabe, dass für alle Fachgebiete mit «überdurchschnittlicher» Kostensteigerung ein Zulassungsstopp verhängt werden muss, lässt zudem rein statistisch bereits erwarten, dass die Kantone jedes Jahr mindestens der Hälfte aller Fachrichtungen keine Zulassung erteilen könnten unabhängig von der absoluten Höhe der Kostensteigerung und vor allem: unabhängig vom Bedarf.

Damit würde auch die politische Forderung «ambulant vor stationär» zur Karikatur: Die Verlagerung von Kosten durch mehr ambulante Behandlungen hätte ambulante Zulassungsstopps für die betroffenen Fachrichtungen zur Folge. Die Vorlage betreibt damit auch Strukturpolitik zugunsten des stationären Sektors und verstärkt die Interessenkonflikte der Kantone. Die geplante, sehr komplizierte und mit viel Bürokratie verbundene Regulierung lässt also nicht einmal wünschenswerte Wirkungen erwarten. Einfacher und nachgewiesenermassen wirksam wäre hingegen eine gezielte Verschärfung und Verstetigung der seit 2013 bewährten Zulassung nach Qualitätskriterien gemäss Artikel 55a KVG: Denn müsste (1) neu die notwendige dreijährige Tätigkeit an einer anerkannten schweizerischen Weiterbildungsstätte auch in der für die $\mathbf{Z u}$ lassung beantragten Fachdisziplin absolviert werden, wären ein bedarfsgerechter Fachärzte-Mix und eine

Die politische Forderung "ambulant vor stationär» wird zur Karikatur wenn mehr ambulante Behandlungen zu ambulanten Zulassungsstopps führen.

einfache Lenkungsmöglichkeit durch die Kantone gewährleistet. Verlangt man (2) zusätzlich einen Nachweis der erforderlichen Sprachkompetenz, würden die $\mathrm{Zu}$ lassung weiter verschärft und die Patientensicherheit verbessert. Diese wirksame und schlanke Lösung wäre nicht nur im Sinne der kürzlich vom Ständerat beschlossenen Regulierungsbremse (16.3360) - sondern vor allem im Sinne eines zukunftsfähigen Gesundheitswesens. 